\title{
BACK TO THE FUTURE - NOT ROCKET SCIENCE: SOME THOUGHTS ON 20 YEARS OF CONSULTATIONS ON THE FUTURE OF THE BVC AND PUPILLAGE
}

\author{
Frances Burton ${ }^{*}$
}

\section{INTRODUCTION}

In the last two decades opportunities for exasperation in the vocational legal education constituency have been mounting as paper after paper has been published (and dutifully responded to by the various stakeholders) on reform of the Bar Vocational Course ("BVC"). This has only recently been at least temporarily stemmed by the report of the newly created Bar Standards Board ("BSB") on Deferral of Call in June 2007, ${ }^{1}$ albeit immediately followed by the announcement of further reviews of the BVC and pupillage. This is not to mention a plethora of consultations and papers, which have gone before, including those earlier considered by the Standing Committee on Legal Education. ${ }^{2}$ However, it looks as though a final definitive decision on

\footnotetext{
* Formerly Director of the BVC by Open Learning, Bristol Institute of Legal Practice, University of the West of England, Vice President Association of Women Barristers, Vice-Chairman International Bar Association Academic and Professional Development Committee. An earlier version of this and the AWB's paper proposing a BVC sandwich course to include a period to replicate the non-practising period of pupillage was debated in the Practice, Profession and Ethics Specialist Subject Section Meeting Panel Discussion "Current Issues in the Vocational Stage of Training" at the annual conference of the Society of Legal Scholars at Keele University on Tuesday 5 September 2006, and again at the Learning in Law Conference at Warwick University on Thursday 3 January 2008. The paper remains work in progress due to the pace of change following the inauguration of the Bar Standards Board and its programme of review. A final version (when and if that might be available!) may be obtained from Frances Burton, frb@frburton.com

${ }^{1}$ Published 8 June 2007, available at www.barstandardsboard.org.uk.

${ }^{2}$ The most relevant previous Bar Council reports are summarised in Appendix 5 of the report, dated 27 November 2007, of the Entry to the Bar Working Party chaired by Lord Neuberger of Abbotsbury and are: Report of the Bar Entry and Training Working Party, 1991 ("Taylor"); Report of the Working Party on Financing Entry to the Bar, July 1998 ("Goldsmith"); Financing Entry to the Bar, March 1999 ("Tuckey"); Committee to Review Financial Support for Entrants to the Bar, July 2002 ("Mountfield") Response of the Education and Training Committee ("Response to Mountfield"); Bar Council Resolution, November 2002 ("Mountfield Resolution");
} 


\section{SOME THOUGHTS ON 20 YEARS OF CONSULTATIONS ON THE FUTURE OF THE BVC AND PUPILLAGE}

the equally long running debate on "Deferral", notable as the BSB's first indication of a new approach, especially as it was for the first time evidence rather than anecdotally based, may be breaking the vicious circle.

Up to 2006 the only positive factor in this apparently unfocused attack on rainforests was the Association of Women Barristers' 2005 Discussion Paper on the BVC and Pupillage ${ }^{3}$ which, by at last looking at the broad picture, picked out the one macro issue which in fact drives all the micro tinkering with the BVC, and the emotion surrounding both the BVC and Deferral, namely that the $\mathrm{BVC}$, pupillage, obtaining a tenancy and immediately embarking on continuing professional development ("CPD") are all links in an important chain in training for the Bar up to the point at which a barrister can practise independently. This was followed up by a paper delivered by Richard Wilson QC at the BVC Providers Conference of July 2007 proposing much more radical restructuring of the BVC, to include more practitioners' input into skills, more academic work on the "knowledge" subjects of Civil and Criminal Procedure and Evidence, and possibly a two part BVC in which the knowledge subjects were disposed of first, prior to concentration on the barristers' skills, which should then be largely delivered by practitioners and based on Advanced Litigation Modules.

Had this holistic approach to classroom and work-based learning been addressed in the first place, and perhaps a brief glance spared towards the simple principles of Bar education of the past which produced the great advocates of legend, much time, trouble and expense might have been saved, since it is pointless to discuss the content of the BVC (as it was even to consider Deferral of Call) without also considering the present arrangements for pupillage which are now seriously out of date. Thus it is no surprise that even before the publication of the Final Report of Lord Neuberger's Working Party on Entry to the Bar, ${ }^{4}$ set up to look at access and the BVC generally, the BSB set up another committee specifically to review the BVC syllabus, the

Taskforce on Funding Entry to the Bar, July 2002 ("Calvert-Smith"); First Draft of the Report of the Voluntary Scheme Appeals Committee, April 2005; Arrangements for Collecting Contributions, June 2005 ("Southern").

${ }^{3}$ The full 2005 paper "Pupillage" by Kaly Kaul, then Chairwoman of the Association of Women Barristers, which suggested an integration of BVC and part of pupillage in a "sandwich" format, is obtainable from the Editor of the AWB Newsletter (awbeditor@aol.com). A further paper on pupillage is planned for issue shortly by the current Chairwoman, also a criminal practitioner on the South Eastern Circuit and for some years the Circuit's Representative on the AWB Committee.

${ }^{4}$ The Entry to the Bar Working Party was set up in late 2006 by Geoffrey Vos QC, then incoming Chairman of the Bar, and its membership comprised inter alia representatives of the Bar Council, including the Young Bar, and Diversity specialists including the Chairman of the Diversity Law Association. Its final report is at www.barcouncil.org.uk. 
Wood Working Group, ${ }^{5}$ chaired by Derek Wood QC, formerly Treasurer of Middle Temple and Principal of an Oxford College. Then we hear that there are next to be separate BSB reviews in 2008-9 not only of pupillage but also of CPD for the Bar, in which the BSB aims to set out its stall for the provision of a holistic solution, but without (so far) any indication of the necessary links between the three stages.

\section{THE PRESENT REGIME}

In order to understand the dynamics of these debates some grasp of the present regime is essential. In summary, since 1989 the BVC has been a single academic year, skills-based course targeted towards teaching in class as to $65 \%$ of its content - as follows: the barristers' practical skills of advocacy, conferencing (ie interviewing instructing solicitors and their lay clients prior to representing them in court or otherwise advising them on the law and practice), negotiation (settling cases), writing opinions, drafting court and other documents, practical legal research and professional ethics (ie applying the Bar Code of Conduct) and - as to the remaining 35\% of the course - teaching, either in class or online, as follows: the "knowledge" elements of civil and criminal procedure and evidence and human rights. No new law as such is therefore taught on the course, since this is expected to be learned at the previous academic stage where the "core subjects" of English Law, called the 7 foundations of legal knowledge, are examined either as part of the 2-3 year undergraduate law degree or on the fast track conversion course for non-law graduates, the "Graduate Diploma in Law" ("GDL", formerly known as the "Postgraduate Diploma in Law" or "PgDL") which is taken either in 1 year full time or 2 years part time. The BVC is then followed by 12 months of practical training in "pupillage" in Barristers' Chambers (the first 6 months of which is a work shadowing experience, followed by a further 6 months when the pupil, still under some supervision, may accept work on his or her own account). The object of the Deferral debate was to prevent those who had not done the 12 months' pupillage from being Called to the Bar at all even if they had graduated from the BVC (which is in itself a degree, its graduates being Called by their Inns of Court to "the degree of the Utter Bar" - the penultimate word being the medieval spelling of "outer"). This attempt to exclude BVC graduates from Call - or use of the title - was said to be on suspicion that the BVC alone was an inadequate foundation for the profession of Barrister, that the public was misled, and that allowing Call before pupillage did not equate to the practical experience required in the medical profession (ignoring the recognition that the BVC is a lawyerly training in its

${ }^{5}$ This committee is expected to report in the summer of 2008 . 


\section{SOME THOUGHTS ON 20 YEARS OF CONSULTATIONS ON THE FUTURE OF THE BVC AND PUPILLAGE}

own right which has traditionally in the past been successfully recycled in a useful practical fashion in careers other than that of court advocate and that this tradition is preserved in a number of overseas jurisdictions as well as in the UK). However, while there had always been a hunch that the real agenda was to reduce the numbers on BVCs and threats to those already in the profession, the BSB's evidence gathering refuted any such justifications for throwing the baby out with the bathwater, found the public was not misled, and that the proportionate remedy was for pupils simply to be called Pupil Barristers until they had completed their full 12 months pupillage and then received the full practising certificate.

From 1989, the BVC was provided only by the London based Inns of Court School of Law ("ICSL") but from 1996 the right to provide the course was devolved to 8 nationwide law schools at a variety of locations. Courses may thus be found in some universities, within London and regional branches of the College of Law (a charitable foundation) and some at the commercial provider, BPP Law School, in London and Leeds.

Prior to 1989, the ICSL was the main provider of an almost entirely academic Bar Examination, with the College of Law (formed from the amalgamation of the Law Society's School of Law for solicitors and the long established law tutors Gibson \& Weldon), which also delivered tuition by a "postal course" on the lines of the traditional $19^{\text {th }}$ century correspondence courses. It should be noted that while the BVC was greeted as a great innovation in 1989, the old style Bar Examination (which had qualified the great advocates of the $20^{\text {th }}$ century) was found insufficiently worth scrapping that upon creation of the BVC it was itself deregulated and devolved to the various teaching institutions for the next decade, as a qualifier for those of the Commonwealth jurisdictions which recognised Call to the Bar in England and Wales as sufficient for local qualification at their own Bars. At least two attempts were made to modify it as a permanently less skills based species of BVC for those jurisdictions as well as for UK candidates who wished to work in employed practice or in those contexts outside the law altogether where a law background was nevertheless appreciated.

However, during the whole of the time from 1989 when the new BVC was created by the ICSL, it was clear that the new course carried with it certain new problems: reform began almost immediately to be discussed to address the rising student costs which such a long and labour intensive course inevitably brought with it, and in the run up to the design of the new Legal Practice Course for solicitors (the Law Society's own version of a skills based course to replace their academically focussed qualifying Law Society Examination) envious glances were cast towards Australia and Canada where much shorter courses and more work based learning were the norm. Various methods of tackling this perceived evil of rising costs and consequent student debt have included pressure for a shorter, somehow different, course which 
could be delivered more cheaply, producing less financial burden for students. As mentioned above, no one, however, found the Philosopher's Stone, which would transform this leaden educational deadweight into the golden experience, that everyone, especially students, seemed to think it ought to be.

\section{THE NEXT STAGE}

High hopes were raised by the post Clementi $^{6}$ separation and restructuring of the Bar Council's regulatory and representational roles, which created the Bar Standards Board (the originator of the 2006-7 Deferral of Call consultation). The report following this consultation, the BSB's first chance to show that it was cutting a swathe, seems finally to have had the muscle to knock on the head the particular irrelevancy of Deferral. Tackling this issue first was an excellent public relations move by the BSB. While not achieving any of its perceived goals, Deferral would have put a stop to the longstanding tradition of Call to the Bar by their Inns of Court of two categories of BVC student: (i) a significant proportion of overseas aspiring lawyers who take the English Bar's BVC before returning to their Commonwealth jurisdictions, and (ii) an equally significant body of UK based students proceeding into government or other careers where a law background is of practical validity in recognition of the valuable training they had received alongside those who did aspire to practise in the courts of England and Wales. It is therefore most encouraging to see the new Board grasping the obvious nettle and explicitly saying so in its published papers: that is, that someone needs to look at these Bar education issues as a whole since they are so interwoven that change in any one will impact significantly on the others. The obverse of this coin is that it also serves notice that a holistic view simply suggests how all the currently contentious issues might fall into place if for the first time considered as a whole.

\section{THE MISCHIEFS TO BE ADDRESSED: COSTS, DIVERSITY, COURSE CONTENT AND RIGOUR}

Much has been made in the multi consultations, as well as the popular press, of the rising costs of access to the Bar. On top of the escalating mountain of graduate debt generally, this is a valid issue as it also adversely affects the commitment to diversity which is enshrined in the Bar Code of Conduct and in the articulated ethos of the profession. The final concern is of the dubious content and suspicions of lack of rigour of the present BVC,

\footnotetext{
${ }^{6}$ Report of the Review of the Regulatory Framework for Legal Services in England and Wales, available at www.legal-services-review.org.uk/content/report.
} 


\section{SOME THOUGHTS ON 20 YEARS OF CONSULTATIONS ON THE FUTURE OF THE BVC AND PUPILLAGE}

although closer examination reveals that this by no means entirely substantiated perception is generated principally by the large class size course inaugurated by the then Council of Legal Education in its Inns of Court School of Law in Grays Inn in 1989, which with modifications is still the course delivered by the ICSL, but not replicated by other providers who all designed their own courses in accordance with the Bar Council syllabus when the devolved BVC began to be taught at the 8 validated institutions from 1997. Since that time ICSL numbers have been to some extent reduced and more individual attention also built into the ICSL course, but the generalised misconception nevertheless apparently persists, often in ignorance that other law schools catering for much smaller numbers do things differently.

\section{(a) Costs}

Taking costs first, there is no doubt that a course lasting an academic year will be more expensive than one lasting a shorter time, since the longer a student studies, especially on a full time mode of a course, the more s/he must spend on living expenses as well as on the course fees, and if full time on a demanding course will be unlikely to be able to earn at the same time. While it is true that some students are self funded, either by themselves, their spouses or partners or their parents, or have scholarships (most notably from the Inns of Court and Chambers whose scholarships and bursaries usually allow some drawdown towards the BVC year) there are many who must work in vacations and at weekends in order to support themselves. On the provider institutions' side, their staff must be paid and up to date teaching resources and accommodation must be funded.

Therefore there is clearly something to be said for a shorter course. In Vancouver, British Colombia, the qualifying course is 16 weeks, in Australia around 6 months (though the different states have different provision), in the USA no more than 5 and in Europe the range stretches from zero provision to 6 months or less, with varying degrees of work based learning to follow, much like our pupillage. For this reason Pupils at the Bar in England and Wales have from time to time proposed a much shorter course, usually pointing to much wasted time at one particular BVC provider where students are much left to their own devices to learn. However anecdotal evidence at present emerging from the BSB's current review of the BVC does not suggest that a significantly shorter course is going to be proposed, nor the "sandwich" provision suggested by the AWB paper, although there may be some tinkering with the precise syllabus, possibly leaving some of it for the pupillage stage. It would appear, then, that the only way to cut costs is for students to continue to borrow, or save ahead of their BVCs, or to take a part time course, preferably making as much use of open, flexible or blended learning as 
possible, by learning the knowledge components on line. More use of open learning type courses was amongst the Neuberger Report recommendations.

\section{(b) Diversity}

It should be remembered that the BVC was originally designed to introduce a skills based training at a time when the only alternative had for many years been a written examination for which it was said that students simply "crammed" much as they had done since the $19^{\text {th }}$ and early 20th centuries when "reading for the Bar" was either a gentlemanly self administered occupation or a simple process of bolting on to mostly Oxbridge Law Degrees mastery of the content covered by simple examination papers in Evidence and Procedure. This was traditionally achieved with or without the help of the leading "crammer" in the genre, Messrs Gibson \& Weldon of glorious memory, one of the two parents of the 1960s creation of the College of Law.

Various unsuccessful or sadly half-baked attempts have been made to address these twin horrors of costs and diversity which inevitably impact on each other, alongside the generalised (and often not convincingly articulated) concerns (largely based on unease with the quality of the course at one provider) about whether there should be changes to the composition of the BVC. The diversity results now speak for themselves. The Bar Council's statistics show that while men and women are now roughly equal at the entry point of $\mathrm{BC}$ and pupillage, this changes within 5 years of the start of their careers when women begin to leave the Bar and men advance more quickly, although there is now good minority ethnic representation at least in the lower echelons of the profession (not replicated above the lower judiciary however). Nevertheless what the Bar Council and BSB are seeking is a greater representation in the profession of ordinary indigenous British people from atypical backgrounds and the Neuberger report confirms that the Bar is not in fact attracting the "brightest and the best".

\section{(c) Course Content and Rigour}

The imbalance between the numbers of students entering the BVC (approximately 2000 annually now) and the supply of pupillages (currently approximately 500 annually) has also been a chronic cause for concern, together with a suspicion that the large numbers of BVC graduates - four times the necessary supply seeking the too few pupillages - automatically meant the BVC was too easy, and this was said to be much more critical an issue in the context of the proposal for Deferral of Call. However until now all this has been mostly a chronic background "noise" rather than ever culminating in a structured campaign and it appears that the only recently with 


\section{SOME THOUGHTS ON 20 YEARS OF CONSULTATIONS ON THE} FUTURE OF THE BVC AND PUPILLAGE

the Neuburger Report and the Wood Committee has any coherent thought apparently been given to a way forward out of this plethora of lamentation and into some workable future plan. What it comes back to is that the BVC needs to be examined in detail, and in consultation with the profession, for optimum content, together with and in relation to the optimum content of pupillage. To some extent the Neuberger and Wood committees have been attempting to tackle this goal. It is, after all, training for the Bar that is the subject of discussion, and it must be logical that if it was thought (at the time Deferral of Call was discussed for this very reason) that it was right for there to be a mix of formal class training and work based learning for the medical profession, some thought ought to go into the interface between these two types of learning for the student barrister. To do this, the cooperation of the profession as a whole, and not simply a few Bar Council and BSB committee members, needs to be engaged.

\section{NEUBERGER AND WOOD}

The Neuberger Report ("Neuberger"), published on 27 November 2007, has considered most of the relevant previous consultations and reports and Appendix 5 of the Report provides a helpful overview of the most relevant of those though it misses some extremely relevant research, including Professor Joanna Shapland's most recent report for the Bar Council in 2006 (only privately circulated) which looked at issues extremely central to both the BVC and pupillage, namely to what extent the practising Bar might be willing to participate in a more innovative approach to both the BVC and pupillage, for example, even some sort of sandwich course as suggested by the AWB. Professor Shapland has prepared a number of reports on the BVC and pupillage $^{7}$ and it is a great pity that her most recent research was not immediately followed up and indeed one hopes that it could be by the time the Pupillage Review Working Group is constituted later this year.

The way in which Neuberger is different from earlier reports, and foreshadows what may come out of the Wood Committee when their report emerges during the summer of 2008, is that it provides a list of recommendations, which although daunting in its number (55) probably most of which are not even relatively quickly attainable, does flag up issues which have been mentioned, in most cases more than once, in previous review and

\footnotetext{
7 Professor Joanna Shapland, Institute for the Study of the Legal Profession, University of Sheffield, has prepared reports for the Bar Council since 1989, including on the ongoing careers of the first students on the ICSL inaugural BVC. One of her most useful reports is "Good Practice in Pupillage" (1998, now out of print but available from the Bar Council) which it would be particularly useful to follow up now.
} 
yet then apparently discarded onto the back burner if not directly into the bin. The real difference may be in whether the BSB now has the vision to see which need to be prioritised, the muscle to take them forward and, most importantly, actually does make them happen. For a profession which likes to be paid for talking, it is curious that so little that was in its interests has been implemented previously. Perhaps the explanation for this lack of progress is that a keen business case has to be made to achieve obviously desirable changes.

The Neuberger recommendations are divided into 7 chronological sections, rather like Shakespeare's Seven Ages of Man, addressing the way the Bar and its institutions should interact at the stages of (i) Secondary Education in Schools, (ii) Tertiary Education in Universities and other graduate education providers, (iii) the Vocational Stage of the BVC at BVC Providers, (iv) the Training Stage of Pupillage in Chambers or elsewhere, (v) in initial Tenancy or employment, and (vi) in ongoing practice when retention is an issue; finally (vii) Statistics, Monitoring and Funding, which underpin the earlier sections..

It should be remembered that Neuberger was set up by Geoffrey Vos QC, then Chairman of the Bar, to look primarily into Entry to the Bar so it is concerned to a great extent with, first, establishing whether the Bar is getting the best and brightest recruits (the answer to which seems to be "No") although this is the issue about which many independent evaluators have the largest credibility gap, and, secondly, securing those apparently longed for best brains from atypical backgrounds. We have to wait for the Wood Report (of the BVC Review Committee) to address content of the BVC, although even now it already appears that the opportunity for integrations between the BVC Pupillage has once again been missed. There is no space to consider here more than those recommendations which impact directly on the issues of the cost and content of the Bar's qualifying course which has been the main theme of consultations over the past 20 years. However along the way "Neuberger" offers some useful insights into (1) Costs and (2) Content of the BVC and Pupillage.

\section{NEUBERGER'S INNOVATIVE COSTS PROPOSALS}

Taking the hot issue of costs from section (vii) first, Neuberger has certainly learned from the catastrophic reception of the financial proposals in Mountfield and its spin offs, as well as Calvert-Smith (2002), Goldsmith (1998) and Tuckey (1999) (of which Mountfield most, very much irritated the practising Bar). Neuberger proposes, first, a loan scheme similar to that for undergraduate student loans which has now been in place for almost a decade (though hopefully a contemporary scheme would be more successfully managed this time) and, secondly, an innovative sponsorship scheme which 
would enable those employed barristers who cannot actually offer pupillages (since this impacts adversely on the cost centred budgets of the corporations and institutions which employ them) to persuade their employers to fund such pupillages. This seems an inspired idea and is not unlike the corporate funding available to university students for which such companies and institutions can see a business case.

The Employed Bar would no doubt be more than willing to consider such a sponsorship scheme since BACFI (the Bar Association for Commerce Finance and Industry, which is much longer established than the Employed Bar Association) not only considered, but actively promoted an initiative for a pupillage course for their members some years ago. This initiative was the brainchild of its then Chairman (now Vice-President and also a Vice President of the Association of Women Barristers and Bencher of Inner Temple, Susan Ward, who is General Counsel for a banking organisation in the City, and was coincidentally the first Chairman of the Employed Bar Association).

Both these schemes also go some way to meet the needs of those who seek to make the BVC a genuine trainer for alternatives to the self employed or employed Bars, that is for those who either decide the Bar is not for them after all, or those who turn out not to have a real aptitude for practice in either context (which can certainly happen as students at point of BVC entry have many misconceptions about both the Bar and the BVC). The two schemes comprise an extremely practical way forward which should be developed in consultation with the banks, which are only too keen to obtain future lawyer customers in their student years who will in due course more than repay this sort of subsidy, and which, despite credit crunches, always have the money to underwrite this sort of venture.

There are of course other ways of reducing the costs of the BVC and of pupillage, which are more properly considered under the heading of the content and delivery of these two important stages of training.

\section{CONTENT OF THE BVC AND INTERFACE WITH PUPILLAGE: STAGES (III) AND (IV)}

It has been generally agreed by all stakeholders, even the various student organisations, that a BVC of some description is necessary. However, there have been radical student suggestions which have produced a case of sorts for significant shortening of the single academic year course from September to June full time (or 2 years part time) and even suggestions, debated by the BVC Providers Group, that there should be no obligation to follow a course at all but that the BVC should be an assessment only pathway for which the fact and style of preparation should be optional. The present specification for the BVC dates from the Report of the Working Party chaired by the Hon $\mathrm{Mr}$ Justice Elias (generally referred to as "Elias") adopted by the Education and 
Training Committee of the Bar Council for use from September 2002, and periodically amended since. Incredibly, this document is currently under review even before the Wood Report is submitted.

The present BVC length, of at least 32 weeks, supported by some new practical suggestions about rigour, is reinforced by Neuberger Appendix 9, which comprises the recommendations from the Draft Report of a current Sub-Committee of the Bar Council, a Working Group chaired by Richard Wilson QC, a black silk from Bedford Row, which was the foundation of his paper at the BVC Providers Conference of July 2007 already mentioned. It is interesting that Richard Wilson also supports the return of national assessment (last seen in the old style Bar Examination in the 1990s), in which he envisages a nationally set examination, marked locally to nationally set rules and standards, by experienced tutors at the validated institutions where students are registered and taught, a new BVC specification and more rigourous quality rules, reflecting both the increasing rigour of practice at the Bar and its increasing specialisation. These proposals (with a modern twist and without abandoning the skills) revert very closely to the early mix of the old style Bar Examination, but with some polish from the new ICSL BVC of 1989, as practised at BPP Law School in the early 1990s, when that law school was set up to modernise that pathway to the Bar immediately after the ICSL went over to the BVC.

At that stage, the ICSL's alter ego, the CLE, assumed a loosely advisory role, sharing their old materials and some guidance on delivering them with university law departments which had decided to offer a course, while the CLE retained the tasks of setting, arranging marking and moderating, and holding the examination boards for the national examination. This worked extremely well in a well run law school, such as BPP, and not at all badly in less well run institutions of which there were some whose students regularly did not pass. Students very quickly formed their own views of where to go to ensure that they passed the national examination, soon getting the hang of choosing where to enrol or if necessary moving to a provider delivering capable tuition (necessary in those days as the CLE did not validate or quality assure any courses unlike the present position whereby the BSB is the regulator). BPP also offered, particularly for those foreign students who could not get onto the ICSL's BVC, or home students who were not sure if they wanted to practise or not, some advocacy and other skills training, and a series of extra curricular lectures which provided a well rounded preparation for the nationally set Examination. Together with the Inns' input (Cumberland Lodge/West Dean weekends, Dinners, social events, EU institutions' trips, education sessions similar to today's Education Days) this provided a real introduction to the spirit of the profession and took most of the demands of the collegiate emphasis of Bar education off the providers. In the context of such a nationally set assessment it would be good to see the Inns taking a 


\section{SOME THOUGHTS ON 20 YEARS OF CONSULTATIONS ON THE FUTURE OF THE BVC AND PUPILLAGE}

larger part again, for which they have their own voluntary tutor force, and more support from the Circuits.

These suggestions, although probably not welcome to the providers who might see diminishing BVC numbers, seem only right in a context where there is widespread discussion in the practising profession about the relative values of a BVC qualification from different providers. However providers could always make up their revenue with CPD provision and the additional Masters courses that Richard Wilson also envisages to "finish" those (significant numbers of) BVC graduates who never intend to go on to practise at the self employed or Employed Bar.

It is fair to say that the decision to open up both teaching and assessment of the BVC to outside providers, which took place at a time in the mid 1990s when the present, demonstrably highly innovative Lord Chief Justice, Lord Phillips of Worth Matravers, was the judge presiding over the CLE, did raise consistency concerns at that time which have only become more marked. It is also clear that there is an apparently unanticipated marked divergence not only in course design but also in teaching standards as the 8 providers have opened more branches and use their licence to customise their courses ever more creatively. However, despite periodic grumbles elsewhere, only one London provider which does not provide a full week's teaching is consistently criticised by students (although it is fair to say there is a lot a BVC student should be doing in independent study out of class). If the Bar is going to meet the challenges of contemporary practice, national assessment is probably an essential step in the right direction and not before time.

If we were to adopt the practitioner orientated content envisioned by Richard Wilson in his 2007 BVC Conference paper, students would get a basic knowledge of criminal and civil litigation at a general introductory level and then choose from a number of specialist Advanced Litigation Options. They would have Practical Legal Reasoning and Evidence assessed as skills; more Evidence integrated into skills courses; a unified Mediation Advocacy course; a reformed negotiation course on a level with those offered by leaders in the field; and assessed Forensic Accountancy and Equality and Diversity principles, together with Practice Management skills comprising the "basic principles of how to run an effective modern professional practice at the Bar" together with some "office skills" (recognising that in most Chambers members of the Bar - unlike solicitors - are responsible for all their own typing, and, although clerks negotiate and bill for their fees, it is a barrister's responsibility to keep a record of time spent so that it may be billed accurately). All these points reflect contemporary practice at the Bar and (with the exception of mediation advocacy which had not yet arrived on the scene in England and Wales) were in use in the early 1990s at BPP either as part of or alongside the nationally examined Bar Examination of the time. 
Richard Wilson also wants to prescribe minimum advocacy time "on their feet" for students, a diploma in Professional Legal Practice for BVC graduates and for most or all of the course to be taught at QAA Level HE4, to satisfy the criteria for a Masters Degree either as a whole or as at Masters Level following completion of a subsequent module.

This Wilson emphasis on the primacy of advocacy may well be the key to the future of a truly contemporary BVC. The International Bar Association's 2007 Annual Conference at Singapore featured a workshop led by the Australian Federal Judge, Justice Annabelle Bennett, who believes that the relationship between judge and counsel is a crucial one and that good communication is the key to a successful outcome. She sees this as the legacy of the great advocates, and that when presenting their cases in courts counsel need to think about what the judge really needs to know.

Her views are well known in Australia. She suggests what is wanted is "good old fashioned advocacy skills" and that "one of the great skills of the common law system is oral advocacy. Through oral argument a judge can clear up a misconception she or he may have". Despite most judges now reading the papers before a hearing, Justice Bennett thinks that "being able to hear counsel, ask questions and get assistance means that the judge has a much better idea of the case" and "A good advocate is not talking to a computer, a brick wall. She or he is speaking to a person who needs to be persuaded". In leading the workshop she explained that she engages with counsel for reasons of natural justice, so that the way she is thinking is put into the transcript and that engaging with counsel means that her attention is more focused. In doing this she believes that "the lawyers are working with me and we have a mutual interest in the result". Of course she does not underplay the importance of preparation and indeed appreciates that this is the foundation of good advocacy, which seems to sum up the BVC and the preparation subjects which underpin advocacy, its most important skill.

The Neuberger report Wilson appendix also envisions a BVC entry standard of a minimum 2.1 degree (or equivalent CPE/GDL grade, presumably a Commendation), an English language proficiency test for both home and foreign students, and an entrance examination designed to test the student's aptitude for the BVC (ie foundations of legal knowledge) and practice at the Bar. These suggestions are coupled with an expressed desire for a reduction in numbers and an improvement in the quality of BVC graduates, although it is also pointed out that implementing the tests and the raised entry levels would be likely to achieve the desired reduction and raising of standards without any such numbers targets being set.

\section{THE AWB'S VIEW}

Richard Wilson, however, is not the only source of radical suggestions for the improvement of the BVC and its closer links with radically reformed 
pupillage. Building on their sandwich course proposal in 2005, the current Chairwoman of the AWB is drafting a new paper on pupillage alone. The AWB has a substantial student, pupil and young tenancy and Employed Bar membership, as well as a number of senior practitioners who between them have seen every stage of the old style Bar Examination and the post 1989 BVC. The Association's senior members have also seen every stage of pupillage from the informality of the 1960s to the present OLPAS and nonOLPAS paid pupillage structure from which any deviation in the former tradition of the Bar to provide some voluntary work experience in pupillage for Commonwealth students returning overseas is now rigidly controlled by the Bar Council's "waiver" system. They were thus well placed to think around practical proposals, although as will be seen this debate has been going on so long that not even the AWB's proposals are "new" as such: they have been advanced before, in the radical 1999 discussion paper "Restructuring Vocational Training for the Bar" which proposed a BVC and Pupillage sandwich course, approved by the General Management Committee of the Bar Council itself on 24 June 1999, to be introduced in 2002, and, incredibly, shelved like so much of the paper that goes through Bar Council committees.

It is a sad fact that the most recent Bar Council Consultation (2005) ("The Vocational Stage of Training for the Bar", generally referred to as "Bell" since it emerged from a working party chaired by Professor John Bell, Past President of the Society of Legal Scholars, and concentrated on the future content of the BVC) was conducted outside the simultaneous plan to introduce Deferral of Call from 2008. Although Deferral itself has now been wisely killed off by the BSB, since it provoked the final exasperation of consultees suffering from consultation fatigue, it also meant that a number of irritated responses were generated, by Chambers, Inns and both current and recent BVC students, voicing considerable dissatisfaction with the BVC and its costs. It is fair to say that this is likely to happen again when this summer the BSB's Pupillage Review and its CPD review, commence before its BVC Review Committee (the Wood Committee) reports, and the AWB brings out its pupillage paper!

\section{SANDWICH COURSES, FLEXIBLE LEARNING AND COSTS}

If costs alone, especially of a sandwich course, are considered, there is already a mechanism for reducing overall costs to students by teaching those parts of the BVC which need to be included in a formal course through the several Part Time Modes of the BVC offered by the providers over 2 part time years instead of the classic one year full time. These courses are offered either in evenings or weekends, which enables students to remain in employment until the course is completed. The most radical of these is the 
University of the West of England's BVC by Open Learning, a part time block learning weekend course which is supported by intervening study periods where the knowledge is learned online, as is much of Opinion Writing and Drafting, and parts of the Options. This is a system which actually enables students to receive more individual attention than is the case in a fully class based course because of the use of Blackboard software to create a Virtual Learning Environment where work is submitted regularly online in exchange for suggested answers and students' input either monitored (if it is for example on a discussion board) or returned with comments by tutors (on line or in printed off hard copy). There is no doubt this produces more effective feedback, with less burden on the tutor, than can possibly be achieved in a face to face class, and also draws on that learning autonomy which is one of the specific Benchmark qualities of "graduateness" which the Benchmarking process seeks to encapsulate. Benchmarking was first proposed which a student should have brought to the BVC from the academic stage of training.

Moreover, the ethos of this self reliant learning experience is imparted in an intensive 5 day induction week and the first intake (2005-7) has now contentedly passed out of its final year (with a proportionately higher number of Outstanding and Very Competent grades in their BVC results and a proportionately higher pupillage strike rate than the larger full time course at the same institution). The second intake (2006-8) will emerge in summer 2008, a third intake (2007-9) started in autumn 2007. Recruitment of the fourth intake (2008-2010) is almost complete for entry in October 2008.

Mostly UWE has had to design its own materials, customising them from those used on the Full Time mode of the course (which was a burden on the tutors during the creative stage) but gradually some commercial products are appearing. For example, the Panel Discussion at the 2006 Society of Legal Scholars conference, chaired by Michael Petley of the College of Law (which has already introduced substantial on line work on its LPC in the last 3 years) included Martin Hannibal and Lisa Mountford of Staffordshire University, whose earlier presentation in the same session focused on their own online contribution to vocational teaching, a Criminal Litigation manual with multimedia support. ${ }^{8}$ The Panel was invited to consider to what extent an abbreviated BVC as suggested by the AWB paper could be an innovative basis for an overall restructuring of the BVC and a sandwich pupillage and having had the Hannibal-Mountford presentation immediately beforehand was cautiously impressed with the potential.

${ }^{8}$ Published by the Oxford University Press, also publishers of the ICSL BVC manuals, originally developed by the ICSL in 1989, now republished annually. All providers issue these manuals to their students whether or not they also issue their own materials (which many do, preferring their own teaching styles). 


\section{SOME THOUGHTS ON 20 YEARS OF CONSULTATIONS ON THE FUTURE OF THE BVC AND PUPILLAGE}

Following on from such a flexible course, BVC students who have financed themselves through a BVCOL by working throughout might be able better to complete pupillage part time, as is considered by "Neuberger"could be done. This would have to be achieved by lifting the present embargo on a pupil working during pupillage (other than in the traditional part time evening and weekend newspaper and law report editing, or reading publications for libel) and instead permitting pupils to work part of a week or a month (depending upon the employment available) and extending the pupillage beyond the traditional year. Other suggestions revolve around improving arrangements for pupils to be self financing from earnings in the second (practising) six months of a full time pupillage. Much detail needs to be worked out here, which will be for the BSB's Pupillage Review Working Group to do, but if the principle is accepted that pupillage has to be made more accessible the detail could duly follow.

The real benefit of the sandwich proposals, however, would be seen in the coherent progress of a Bar student from BVC application to junior tenancy (ie in the streamlining of the practitioner BVC to "second six" pupillage and on to tenancy transition). Since first, anyone who obtained a BVC place would also have some pupillage experience of "hands on" work experience in Chambers as well as of graduating from the new sandwich BVC, but only those who had successfully shown aptitude during the in Chambers sandwich part of the BVC would proceed to the "second six", which would be the operative part of pupillage (as now), resulting in a full practising certificate.

The remaining BVC graduates would have to seek out other avenues, either at the self-employed Bar or outside the Bar altogether (which is when a "bolt on" specialist Masters course, as also suggested by "Wilson" might be considered if the BVC was not a Masters in itself). This would serve to control numbers in a manageable and ethical manner without making the qualification so hard, or even impossible for some minorities, to achieve that, as the AWB warned, "we destroy our own valuable profession."

Amongst other reformers, the AWB agrees with Neuberger in urging that "we must make it a qualification worth having in its own right, with recognised training and skills." ${ }^{10}$ In this respect, some regard must be had to the entry point at BVC application level, currently set at a 2.2 degree (in any discipline if an LLB is not held and the CPE/(Post) Graduate Diploma in Law is held). There have been arguments for a long time favouring raising this standard to a 2.1 (with discretion from the regulatory body, the BSB, in the case of a 2.2) and recent consensus amongst BVC Providers that it is counterproductive to consider applications from those with Thirds even where

\footnotetext{
${ }^{9}$ Above $n 3$.

${ }^{10}$ Ibid.
} 
discretion is exercised suggests that this may be an essential step to limit wastage of weak students.

Again this is far from new. "Taylor" (1991) first criticised the open door policy on the grounds of both wastage and unsuitability for a career at the Bar when a 2.1 was worth a lot more than it is now in most degree awarding institutions, and the debate has rumbled on for the ensuing 16 years while more and more weak students struggle through the BVC by taking individual bites at the resit cherry till they exhaust permitted attempts and have to give up, or else graduate as (still) weak students.

These students, if they have a real interest in and passion for the law, should be pointed in the direction of more easily attainable qualifications of which there are several recognised in this country. And, if there are definable problems about qualification without Call to the English Bar in certain of our Commonwealth jurisdictions (such as the West Indies where there are particular difficulties) the Inns which have traditionally been the focal educational point in such countries, and the Bar Council, (which includes every year in its annual plans and budgets support for foreign common law jurisdictions), should consider what could be done in other ways to help students from these foreign out posts of the common law who cannot obtain a BVC place in the modern context. Indeed, when he was Attorney General this was a project of Lord Goldsmith's which he might well have been invited to progress further now he is no longer in office, especially as his other interest during his years as Attorney-General was to achieve somewhere the establishment of an Open Learning BVC onto which could be sent CPS personnel who had never had the opportunity to take a professional qualification but who could not be spared, even in the early evenings, to attend class in the working week.

\section{CONCLUSION}

The various BVC Consultations have begged as many questions as they have asked to be specifically answered. A much wider debate is required which includes the issue of pupillage since vocational training for the Bar needs to be looked at as a whole and by the profession in consultation with the BVC Providers: it should not be forgotten that this was originally how training for the Bar was provided - by the old Inns of Court School of Law under the direction of the Inns (ie barristers and judges, and if anybody other than the client is the ultimate consumer, the judges as such certainly have a place in the debate). The fact that the Bar Council inherited control of Bar Education when the Council of Legal Education (the alter ego of the old ICSL) was dissolved, and that the BVC has been devolved to other London and regional law schools as well, does not alter the fact that these providers need a close relationship with the profession for whom they are providing 


\section{SOME THOUGHTS ON 20 YEARS OF CONSULTATIONS ON THE FUTURE OF THE BVC AND PUPILLAGE}

trainees, whether that be with the Inns, the Specialist Bar Associations, the Circuits, Chambers or all of them, and that this is not best served by simple regulation by the BSB. It would in no way detract from the BSB's regulatory role - and indeed its other usefully supportive roles, such as in their relations with overseas jurisdictions which still wish to use the BVC to give their lawyers a world class qualification - if a structure were developed which made more use of the practising profession as such (ie not simply of those practitioners who sit on Bar Council and BSB committees) to steer a reformed $\mathrm{BVC}$ in a positively practical direction for the benefit of profession and public alike.We need to go back to basics, or even back to the future, to utilise the input and free tutor force of the Inns in collating the contribution that now needs to be made by the practising profession - with considerable benefits to Chambers - to modernise the BVC and pupillage, in partnership with the BVC Providers. Then it might be time to talk about developing the BVC wholly to Masters level and/or for a Masters or an MBA equivalent to upgrade the BVC qualification for those who do not want to stay at the self employed or employed Bars, and to hone the BVC to take advantage of all the technical advantages and sophisticated know how which contemporary advances offer. 